\title{
Ethanol Production from Seaweed, Enteromorpha intestinalis, by Sepa- rate Hydrolysis and Fermentation (SHF) and Simultaneous Saccharifi- cation and Fermentation (SSF) with Saccharomyces cerevisiae
}

\author{
YuKyeong Cho, Min-Ji Kim, and Sung-Koo Kim*
}

접수: 2013년 6월 15일 / 게재승인: 2013년 10월 18일

(C) 2013 The Korean Society for Biotechnology and Bioengineering

\begin{abstract}
Ethanol productions were performed by separate hydrolysis and fermentation (SHF) and simultaneous saccharification and fermentation (SSF) processes using seaweed, Enteromorpha intestinalis (sea lettuce). Pretreatment conditions were optimized by the performing thermal acid hydrolysis and enzymatic hydrolysis for the increase of ethanol yield. The pretreatment by thermal acid hydrolysis was carried out with different sulfuric acid concentrations in the range of 25 $\mathrm{mM}$ to $75 \mathrm{mM} \mathrm{H}_{2} \mathrm{SO}_{4}$, pretreatment time from 30 to 90 minutes and solid contents of seaweed powder in the range of 10 $16 \%(\mathrm{w} / \mathrm{v})$. Optimal pretreatment conditions were determined as $75 \mathrm{mM} \mathrm{H}_{2} \mathrm{SO}_{4}$ and $13 \%(\mathrm{w} / \mathrm{v})$ slurry at $121^{\circ} \mathrm{C}$ for $60 \mathrm{~min}$. For the further saccharification, enzymatic hydrolysis was performed by the addition of commercial enzymes, Celluclast $1.5 \mathrm{~L}$ and Viscozyme L, after the neutralization. A maximum reducing sugar concentration of $40.4 \mathrm{~g} / \mathrm{L}$ was obtained with $73 \%$ of theoretical yield from total carbohydrate. The ethanol concentration of $8.6 \mathrm{~g} / \mathrm{L}$ of SHF process and $7.6 \mathrm{~g} / \mathrm{L}$ of SSF process were obtained by the yeast, Saccharomyces cerevisiae KCTC 1126 , with the inoculation cell density of $0.2 \mathrm{~g} \mathrm{dcw} / \mathrm{L}$.
\end{abstract}

Keywords: Bioethanol, Fermentation, Enteromorpha intestinalis, Saccharomyces cerevisiae

\section{Introduction}

Biomass can serve as the excellent resource to meet the present and future energy demands [1]. Biofuels including bioethanol, biodiesel, biohydrogen and biogas can provide the alternative

Department of Biotechnology, Pukyong National University, Busan 608-737, Korea

Tel: +82-51-629-5868, Fax: +82-51-629-7398

e-mail: skkim@pknu.ac.kr transportation fuels. Bioethanol is a promising transportation fuel as it can replace the fossil fuels.

Current production of bioethanol relies on ethanol from starch and sugars but there has been considerable debate about its sustainability [2]. Lignocellulosic biomass has been regarded as the one of the most prospective biomass because it could be used as inexpensive biomass and there is no competition with food directly or indirectly. However, ethanol production from lignocellulosic biomass tends to require pretreatment under severe conditions due to lignin degradation. Lignin is an aromatic polymer synthesized from phenylpropanoid precursors and it is one of the drawbacks in fermentation, as it makes lignocellulosic biomass resistant to chemical and biological degradation [3].

Seaweed is a third generation biomass for the bioethanol production since it has been known for the lignin-free composition and high carbohydrate content. Seaweed can be grown rapidly comparing to land-based biomass and have been harvested in worldwide. Enteromorpha (sea lettuce) are green macroalgae distributed widely in inter-tidal zones and its growth rate can reach $12.7 \%$ per day [4]. Enteromorpha also features the richness in polysaccharides containing a large amount of glucose, xylose, galactose, glucuronic acid, and rhamnose [4]. Thus, the green algae, Enteromorpha, is great potential resource for bioethanol production.

Bioethanol production requires three major processes for the conversion of polysaccharides into ethanol through pretreatment, saccharification and fermentation. The first-step is thermal acid pretreatment which alter structural integrity of biomass and increase the enzymatic accessibility prior to enzymatic hydrolysis. Enzymatic hydrolysis is second process to hydrolyze the cellulose to oligomeric and monosaccharide as well as decrease the viscosity of hydrolysates, which enables easier 
pumping and stirring [5]. The enzymatic hydrolysis currently has monomeric sugar yields of $75 \sim 80 \%$ and improvements are still projected to $85 \sim 95 \%$ [3]. After the pretreatment and the enzymatic hydrolysis, fermentation was carried out to produce ethanol by yeasts. When two processes, enzymatic hydrolysis and fermentation, were separately performed, it is referred to the separate hydrolysis and fermentation (SHF). However, each process can be simultaneously carried out, which is referred to simultaneous saccharification and fermentation (SSF) process. SSF process has been regarded as the major option due to high overall yields and process integration [6]. SSF process is favorable because it requires low energy consumption and short process time. The researchers implement both SHF and SSF processes to compare the ethanol production efficiency.

In this study, reducing sugar production was optimized by thermal acid hydrolysis and/or dual enzyme treatment. And ethanol production by SHF and SSF processes were compared to demonstrate the potential of alternative process to produce ethanol from seaweed, E. intestinalis.

\section{Materials and Methods}

\subsection{Raw materials and characterization}

The seaweed, E. intestinalis, harvested in October 2010, was obtained from Wan-do in Jeon-nam, Korea. Samples were ovendried at $55^{\circ} \mathrm{C}$ and milled by hammer mill. The crude protein content of seaweed was estimated by Kjeldahl method. Crude lipid was determined by using an ether extraction procedure (Soxtec System 1046, foss, Hoganas, Sweden) after freeze-drying for $12 \mathrm{~h}$. Determination of crude ash was done by incineration at $550^{\circ} \mathrm{C}$ for $3 \mathrm{~h}$. The total carbohydrate content was determined by the calculation.

\subsection{Thermal acid hydrolysis}

The thermal acid hydrolysis condition of E. intestinalis was optimized with three factors of sulfuric acid concentration $(37.5,75 \mathrm{mM})$, treatment time (30 90 min) and solid contents $(10 \sim 16 \%, w / v)$ [10]. The slurry was treated by autoclave at $121^{\circ} \mathrm{C}$ in accordance with each condition and the treatment was performed in triplicate. Samples were filtered and stored at $4^{\circ} \mathrm{C}$ for the determination of reducing sugar content and viscosity.

\subsection{Enzymatic hydrolysis of pretreated seaweed slurry}

Commercial enzymes, Celluclast 1.5 L and Viscozyme L were purchased from Sigma (Novozymes, Bagsvaerd, Denmark) [14]. The $\mathrm{pH}$ of pretreated seaweed slurry was adjusted to 4.5 before the treatment of enzyme mixture of Celluclast 1.5 L (8.4 filter paper unit FPU/ml) and Viscozyme L (1.2 endo-glucanase unit
$\mathrm{EGU} / \mathrm{ml})$. Enzymatic hydrolysis was carried out at $55^{\circ} \mathrm{C}$ in water bath shaker with $120 \mathrm{rpm}$ for $54 \mathrm{~h}$. Enzymatic hydrolyzates were evalulated by reducing sugar contents measurement using DNS method [7].

\subsection{Yeast cultivation}

Yeast, Saccharomyces cerevisiae KCTC 1126 obtained from KCTC was used for the fermentation in this study. The inoculum culture was prepared on YPD agar plate containing yeast extract $10 \mathrm{~g} / \mathrm{L}$, peptone $20 \mathrm{~g} / \mathrm{L}$, dextrose $20 \mathrm{~g} / \mathrm{L}$ and agar $5 \%$ $(\mathrm{w} / \mathrm{v})$. Yeast suspension was incubated at $30 \pm 2^{\circ} \mathrm{C}$ with $220 \mathrm{rpm}$ in a shaking incubator.

\subsection{Ethanol fermentation}

\subsubsection{Separate hydrolysis and fermentation (SHF)}

Pretreatment of seaweed slurry was performed with sulfuric acid and enzymatic hydrolysis. The $\mathrm{pH}$ hydrolysate slurry was then adjusted to 5.5 for the fermentation. The fermentation medium was supplemented with $0.5 \mathrm{~g} / \mathrm{L}\left(\mathrm{NH}_{4}\right)_{2} \mathrm{HPO}_{4}, 0.025 \mathrm{~g} / \mathrm{L}$ $\mathrm{MgSO}_{4} \cdot 7 \mathrm{H}_{2} \mathrm{O}$ and $1.0 \mathrm{~g} / \mathrm{L}$ yeast extract [17]. Fermentation was carried out by the inoculation of yeast suspension with a final cell concentration of $0.2 \mathrm{~g} \mathrm{dcw} / \mathrm{L}$. Samples were withdrawn at $12 \mathrm{~h}$ of interval during the experiment and used for the analysis of sugars, ethanol and organic acid.

\subsubsection{Simultaneous saccharification and fermentation (SSF)}

SSF was carried out in $250 \mathrm{ml}$ flask with working volume 100 $\mathrm{ml}$ of pretreated seaweed slurry. Nutrients were added to the medium; $0.5 \mathrm{~g} / \mathrm{L}\left(\mathrm{NH}_{4}\right)_{2} \mathrm{HPO}_{4}, 0.025 \mathrm{~g} / \mathrm{L} \mathrm{MgSO}_{4} \cdot 7 \mathrm{H}_{2} \mathrm{O}$ and 1.0 $\mathrm{g} / \mathrm{L}$ yeast extract. Fermentation was started by the addition of enzymes mixture and yeast, $S$. cerevisiae KCTC 1126 suspension $(0.2 \mathrm{~g} \mathrm{dcw} / \mathrm{L})$. Fermentation was carried out at $30 \pm 2^{\circ} \mathrm{C}$ for $120 \mathrm{~h}$ and the stirrer speed of $220 \mathrm{rpm}$. Sampling and analysis were performed as described above.

\subsection{Analysis of reducing sugar, monosaccharide and viscosity}

Reducing sugar contents were determined by the 3, 5-dinitrosalicyclic acid (DNS) method with glucose (Sigma Chemical Co. USA) as the standard [7]. Sugars, ethanol and other organic acid were analyzed by HPLC (Agilent 1100 Series, Agilent Inc., USA) fitted with Agilent G1362A refractive index detector (RID). Ethanol, acetic acid and 5-hydroxyl methyl furfural (5-HMF) were analyzed with Bio-rad Aminex HPX-87H column $(300 \times 7.8 \mathrm{~mm})$ and Superguard $\mathrm{C} 610 \mathrm{H}$ column $(50 \times 4.6$ $\mathrm{mm})$ at $65^{\circ} \mathrm{C}$ with eluent of $5 \mathrm{mM}$ sulfuric acid and the flow rate of $0.6 \mathrm{ml} / \mathrm{min}$. Samples were filtered through a $0.2 \mu \mathrm{m}$ filter prior to analysis to remove particles.

Viscosity was measured by Brookfield viscometer (BROOK- 
FIELD DV-III Rheometer v3.1, Brookfield Eng. Inc., USA) equipped with spindle No. ULA, SC4-18 and SC4-34 at $30^{\circ} \mathrm{C}$. Yeast cell growth for the inoculation was measured by UV-Vis spectrophotometer at $\mathrm{OD}_{600}$ and converted to dcw using standard curve.

\section{Results and Discussions}

\subsection{Composition and characterization of $E$. intestinalis}

The composition of E. intestinalis was determined. E. intestinalis contains $31.6 \%$ of crude protein, $1.3 \%$ of crude lipid, $24.3 \%$ of crude ash and $42.8 \%$ of total carbohydrate. In other studies with green seaweeds, Ulva and Enteromorpha carbohydrate contents were approximately $30 \sim 40 \%$ as glucose, xylose, galactose, rhamnose and glucuronic acid [4].

\subsection{Effect of pretreatment condition}

Seaweed, Enteromorpha, requires pretreatment in order to make the carbohydrate accessible to enzymes. The pretreatment of seaweed slurry with sulfuric acid increases the enzymatic digestibility of biomass, giving the higher sugar yield than that without sulfuric acid treatment [8]. Therefore, three different variables of solid content, treatment time and sulfuric acid concentration, were selected as the determinant factors for the pretreatment condition.

The results of reducing sugar yield $(\mathrm{g} / \mathrm{L})$ by $37.5 \mathrm{~mm}$ and $75.0 \mathrm{~mm} \mathrm{H}_{2} \mathrm{SO}_{4}$ concentrations at $121^{\circ} \mathrm{C}$ for $30 \mathrm{~min}$ in E. intestinalis are shown in Fig. 1(a). Yield of reducing sugar $(\mathrm{g} / \mathrm{L})$ increased with the increases of sulfuric acid concentration and slurry content in pretreatment. The increase of sulfuric acid concentration from $37.5 \mathrm{mM}$ to $75 \mathrm{mM}$ produced higher reducing sugar content of $9.2 \mathrm{~g} / \mathrm{L}$ and the maximum yield of $16.5 \%$ was achieved with the $75 \mathrm{mM} \mathrm{H}_{2} \mathrm{SO}_{4}$ at the slurry content of $13 \%(\mathrm{w} / \mathrm{v})$.

However, the increase of slurry content decreases reducing sugar production causing difficulty with rotation. Fig. 1(b) shows the effect of slurry contents and sulfuric acid concentrations on viscosity of slurry. The viscosities of slurry were decreased when solid contents decreased and sulfuric acid concentration increased. It has been reported that increased slurry content led to high viscosity which inhibited the cell growth and medium handling although high solid content provided economic advantages $[9,10]$. High solid content also results in processing problems including high power consumption and reduced conversion [11]. In this experiment, $13 \%(\mathrm{w} / \mathrm{v})$ solid content showed maximum hydrolysis yield, however, further increase in solid content decreased the hydrolysis yield. Therefore, $13 \%$ $(w / v)$ slurry content was used for the ethanol production process.

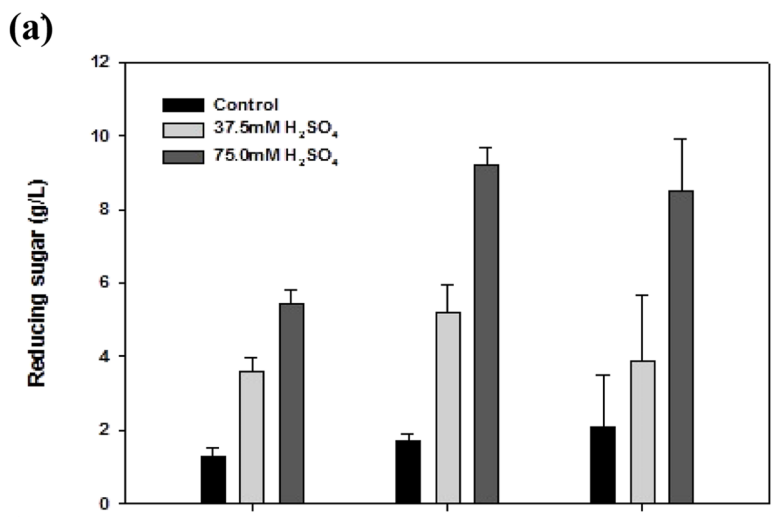

(b)

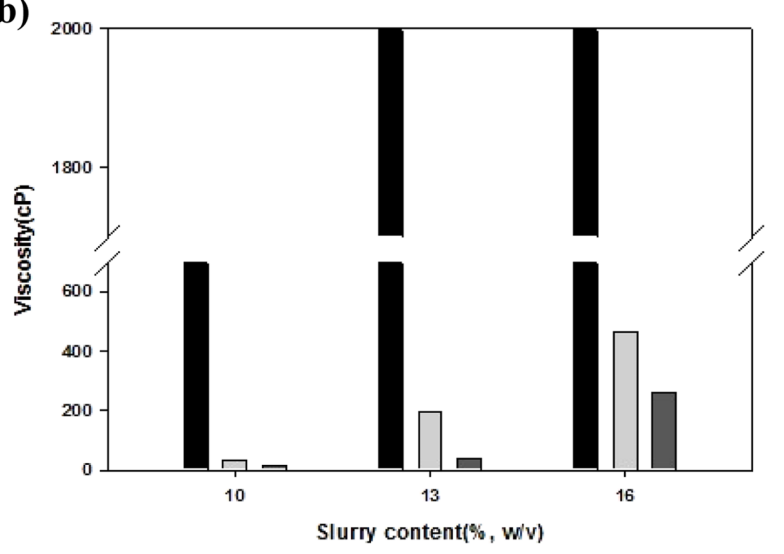

Fig. 1. Evaluation of optimal condition for the thermal acid hydrolysis using concentrations of $\mathrm{H}_{2} \mathrm{SO}_{4}$ and seaweed slurry contents. (a) Production of reducing sugar $(\mathrm{g} / \mathrm{L})$ and (b) viscosity $(\mathrm{g} / \mathrm{L})$ depending on concentrations of $\mathrm{H}_{2} \mathrm{SO}_{4}$ and seaweed slurry contents (w/v).

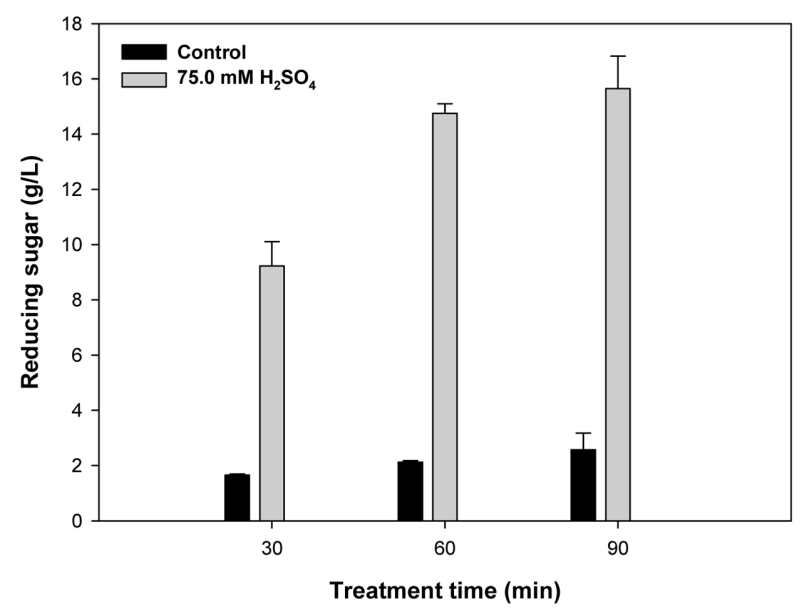

Fig. 2. Production of reducing sugar $(\mathrm{g} / \mathrm{L})$ treated with $75 \mathrm{mM} \mathrm{H}_{2} \mathrm{SO}_{4}$ and $13 \%(\mathrm{w} / \mathrm{v})$ E. intestinalis slurry depending on the treatment time.

Seaweed, E. intestinalis, slurry were treated with time variation and the result of reducing sugar yield were shown in Fig. 2. Using the solid content of $13 \%(\mathrm{w} / \mathrm{v})$, the yield of reducing sugar increased from $9.2 \mathrm{~g} / \mathrm{L}$ to $14.7 \mathrm{~g} / \mathrm{L}$ by increasing the treatment time from $30 \mathrm{~min}$ to $60 \mathrm{~min}$. However, a slight increase 
of reducing sugar yield was observed when treatment time was extended from $60 \mathrm{~min}$ to $90 \mathrm{~min}$. Lu et al. (2007) reported that the increase of treatment time led to the decrease of reducing sugar production which caused sugar decomposition with production of furfural and 5-HMF [10]. Considering the pretreatment efficiency and cost, 13\% (w/v) of solid contents, $75 \mathrm{mM}$ of $\mathrm{H}_{2} \mathrm{SO}_{4}$ and treatment time of 60 min were selected for further experiments.

\subsection{Hydrolysis of $E$. intestinalis by commercial enzymes}

Enzymatic hydrolysis of green seaweed, E. intestinalis, with commercial enzyme mixture was performed after the thermal acid hydrolysis. E. intestinalis was further hydrolyzed by the addition of commercial enzymes, Celluclast 1.5 L and Viscozyme L, to increase the saccharification yield of seaweed.

The enzymatic hydrolysis with commercial enzymes is shown in Fig. 3. The reducing sugar of $20.9 \mathrm{~g} / \mathrm{L}$ with $37.7 \%$ of theoretical yield was obtained using Celluclast $1.5 \mathrm{~L}$ only. Viscozyme $\mathrm{L}$ treatment showed hydrolysis, showing maximum reducing sugar content of $24.2 \mathrm{~g} / \mathrm{L}$ with $43.7 \%$ of theoretical yield. Viscozyme L, a multi-enzyme complex including arabinase, cellulase, beta-glucanase, hemicellulase and xylanase could degrade diverse polysaccharides containing in E. intestinalis whereas Celluclast $1.5 \mathrm{~L}$ degraded cellulose. The hydrolysis efficiency of the mixed two enzymes, Celluclast $1.5 \mathrm{~L}$ and Viscozyme L, was higher than that of individual enzyme treatment. A maximum reducing sugar of $40.4 \mathrm{~g} / \mathrm{L}$ corresponding to $73.0 \%$ of theoretical yield was obtained at the incubation of $36 \mathrm{~h}$ with the mixture of two enzymes. It has been reported that mixed enzymes treatment increased the release of reducing sugar content comparing to individual enzyme treatment [12].

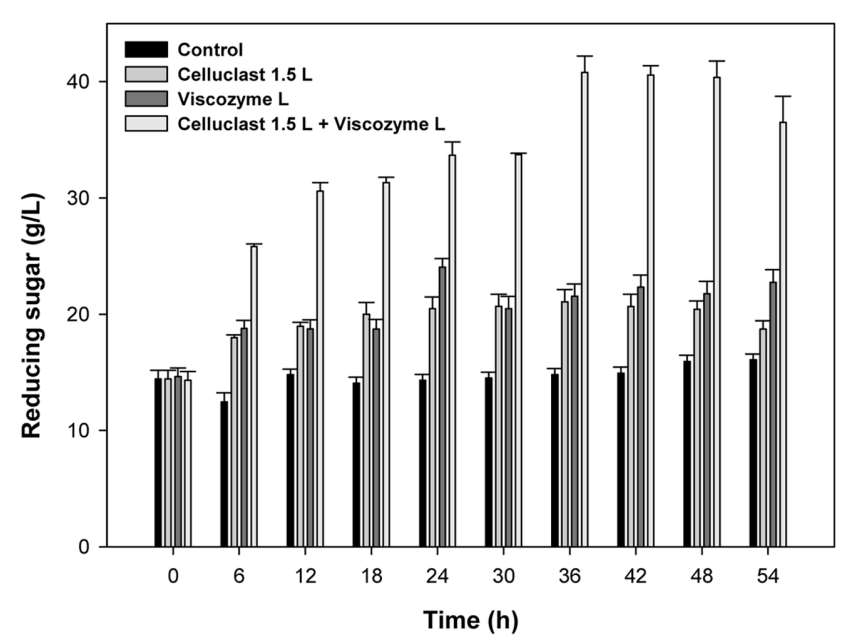

Fig. 3. Reducing sugar production $(\mathrm{g} / \mathrm{L})$ by enzymatic hydrolysis of pretreated E. intestinalis slurry with enzymes, Celluclast $1.5 \mathrm{~L}$ and/ or Viscozyme L.

\subsection{SSF and SHF}

Fermentation was carried out using SHF and SSF methods. In order to compare SHF and SSF, fermentation yields were calculated by assuming that all monosaccharides in the slurry are available for the fermentation. Based on the assumption, ethanol concentration of $8.6 \mathrm{~g} / \mathrm{L}$, corresponding to $30.5 \%$ of theoretical case was obtained at $48 \mathrm{~h}$ in SHF process as shown in Fig. 4(a). The ethanol concentration of $7.6 \mathrm{~g} / \mathrm{L}$ with an ethanol yield of $26.9 \%$ of theoretical case was observed by SSF process as shown in Fig. 4(b). Fig. 4 also shows the time course of reducing sugar consumption, ethanol and inhibitor productions in each process.

In the SHF, reducing sugar was rapidly decreased from $40 \mathrm{~g} / \mathrm{L}$ to $14.7 \mathrm{~g} / \mathrm{L}$ during $24 \mathrm{~h}$ of fermentation. During the same period, a rapid increase of ethanol concentration was observed. However, $10 \mathrm{~g} / \mathrm{L}$ of reducing sugar was still remained at the end of the SHF process. This indicates that non-fermentable sugar monomers in E. intestinalis were not utilized by $S$. cerevisiae during fermentation since the glucose was consumed as a carbon source by the yeast. Similar pattern of reducing sugar consumption and ethanol production was also observed in case
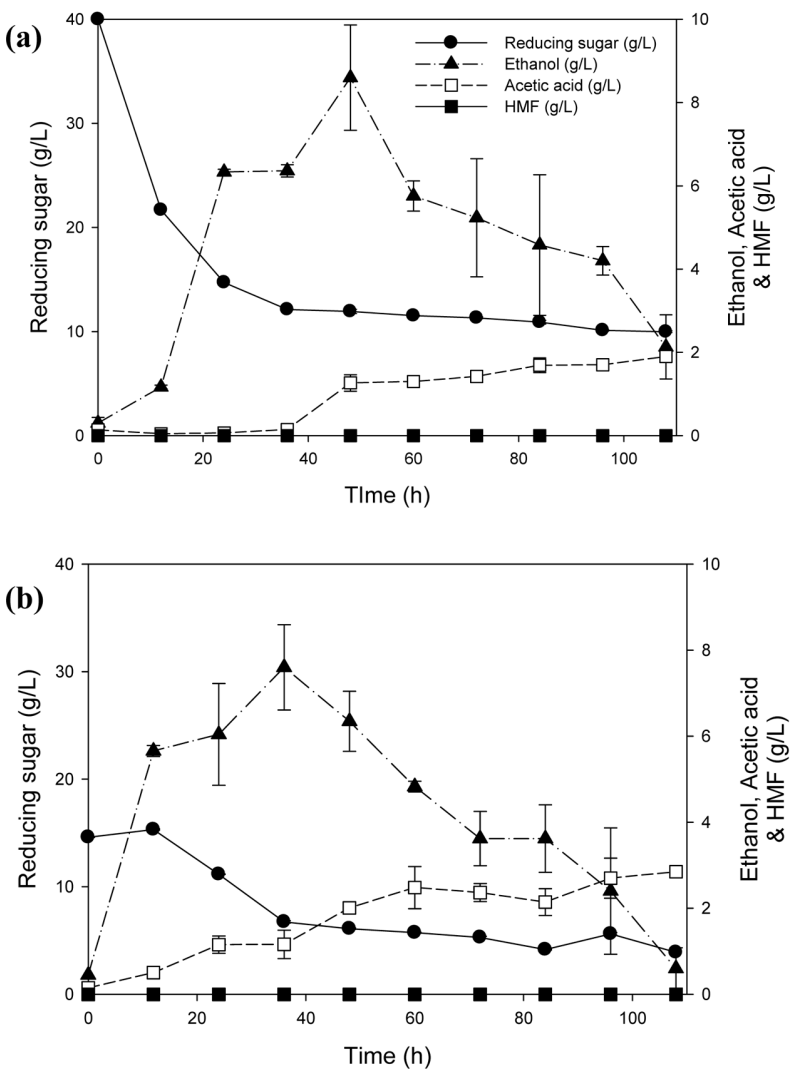

Fig. 4. Fermentation of reducing sugars from thermal acid hydrolysis and enzyme treated $E$. intestinalis to produce bioethanol Changes of reducing sugar, ethanol, acetic acid and HMF concentrations (g/ L) in (a) SHF (b) SSF processes. 
of SSF. The concentration of reducing sugar remained under $10 \mathrm{~g} / \mathrm{L}$ after $36 \mathrm{~h}$ of fermentation. In the SSF, the extent of carbohydrate conversion into reducing sugar was lower than that obtained in the SHF process. This might be the difference in process temperatures of fermentation and enzymatic hydrolysis of treatment. The overall process of SSF was carried out at temperature of $32^{\circ} \mathrm{C}$, which is lower than the optimal temperature of $55^{\circ} \mathrm{C}$ for the action of each enzyme. Although the commercial enzymes had quite different specific activities, SSF process worked better than SHF process, considering the efficiencies of ethanol production and time required for separate enzymatic hydrolysis of $36 \mathrm{~h}$ and fermentation of $48 \mathrm{~h}$.

The ethanol concentrations decreased after reaching maximum ethanol concentrations at $48 \mathrm{~h}$ and $36 \mathrm{~h}$ in SHF and SSF processes, respectively. The decrease of ethanol concentration might be related to the conversion of ethanol to acetic acid. It has been reported that the microbial population was adapted to consume sugar and ethanol when the ethanol was accumulated in the medium thus resulted in reduction of ethanol concentration [13]. Similar result of decline in ethanol production after maximum ethanol production was reported in other study [14].

The changes of fermentation inhibitor concentration during SHF and SSF process are shown in Fig. 4. The increase of acetic acid was observed with the decrease of ethanol concentration as shown in Fig. 4(a) and (b). Acetic acid concentration less than $3 \mathrm{~g} / \mathrm{L}$, lower than inhibitory concentration of fermentation was observed throughout all experiment in SSF and SHF processes [15]. HMF was also major by-product derived from hexoses. However, 5-HMF was not detected in both processes.

Despite the $70 \%$ of hydrolysis, results showed low ethanol production. It showed that all of reducing sugars produced from thermal acid hydrolysis and enzymatic hydrolysis were not utilized during fermentation process. The yeast, $S$. cerevisiae, can utilize C6-monosaccharides as substrate and hardly metabolize other types of saccharide that such as xylose, arabinose [5]. In this study, various types of monosaccharides hydrolyzed from $E$. intestinalis were not utilized because of the limitation of substrate uptake by the yeast. Hsu et al. [5] reported that xyolse in lignocellulosic biomass cannot be efficiently utilized due to the same reason. However, our result shows that the ethanol production amount and yield were higher than other study although the ethanol fermentation was carried out with only $S$. cerevisiae not combination with other yeasts which can metabolize C5monosaccharides [16]. Another reason related to low ethanol conversion was due to rhamnose and glucuronic acid which were handly converted into ethanol by fermentation. Thus, improvement of yeast strains capable of fermenting both hexose and pentose sugars should be applied for the improvement of ethanol production from seaweeds.

\section{Conclusions}

Seaweed, E. intestinalis, is an attractive biomass for bioethanol production due to lignin-free composition and its high carbohydrate contents. The study of bioethanol production process and improvement of saccharification step from E. intestinalis was described in this paper. The application of dual-enzymes, Celluclast $1.5 \mathrm{~L}$ and Viscozyme L, can improve enzymatic digestibility and the conversion of polysaccharide to reducing sugar reached about $73.4 \%$ after $36 \mathrm{~h}$. This results are based on the further studies to increase saccharification yield from seaweed, E. intestinalis.

The highest ethanol concentration of $8.6 \mathrm{~g} / \mathrm{L}$ corresponding to $30.5 \%$ of theoretical yield was achieved in SHF process whereas $7.6 \mathrm{~g} / \mathrm{L}$ of ethanol concentration corresponding to $26.9 \%$ in SSF process was obtained with $S$. cerevisiae. It was concluded that SSF process showed a better efficiency than SHF process, considering fermentation yield and time required for all process.

\section{ACKNOWLEDGEMENTS}

This research was supported by Basic Science Research Program through the National Research Foundation of Korea (NRF) funded by the Ministry of Education (2013R1A1A2059095).

\section{REFERENCES}

1. Rojan, P. J., G. S. Anisha, K. M. Nampoothiri, and A. Pandey (2011) Micro and macroalgal biomass: a renewable source for bioethanol. Bioresour. Technol. 102: 186-193.

2. Alvira, P., E. Tomas-Pejo, M. Ballesteros, and M. J. Negro (2010) Pretreatment technologies for an efficient bioethanol production process based on enzymatic hydrolysis: A review. Bioresour. Technol. 101: 4851-4861.

3. Balat, M. (2010) Production of bioethanol from lignocellulosic materials via the biochemical pathway; A review. Energ. Convers. Manage. 52: 858-875.

4. Feng, D., H. Liu, F. Li, Peng. J, and Song. Q (2011) Optimization of dilute acid hydrolysis of Enteromorpha. Chin J. Oceanol. Limnol. 6: 1243-1248.

5. Hsu, C. L., K. S. Chang, M. Z. Lai, T. C. Chang, Y. H. Chang, and H. D. Jang (2011) Pretreatment and hydrolysis of cellulosic agricultural wastes with a cellulase-producing Streptomyces for bioethanol production. Biomass Bioenerg. 35: 1878-1884.

6. Marques, S., L. Alves, J. C. Roseiro, and F. M. Girio (2008) Conversion of recycled paper sludge to ethanol by SHF and SSF using Pichia stipitis. Biomass Bioenerg. 32: 400-406.

7. Tomas-Pejo, E., J. M. Oliva, A. Gonzalez, I. Ballesteros, and M. Ballesteros (2009) Bioethanol production from wheat straw by the thermotolerant yeast Kluyveromyces marxianus CECT 10875 in a 
simultaneous saccharification and fermentation fed-batch process. Fuel. 88: 2142-2147.

8. Kahar, P., K. Taku, and S. Tanaka (2010) Enzymatic digestion of corncobs pretreated with low strength of sulfuric acid for bioethanol production. J. Biosci. Bioeng. 110: 453-458.

9. Rosgaard, L., P. Andric, D. J. Kim, S. Pedersen, and A. S. Meyer (2007) Effect of substrate loading on enzymatic hydrolysis and viscosity of pretreated barley straw. Appl. Biochem. Biotechnol. 143: $27-40$.

10. Lu, X., Y. Zhang, and I. Angelidaki (2009) Optimization of $\mathrm{H}_{2} \mathrm{SO}_{4^{-}}$ catalyzed hydrothermal pretreatment of rapeseed straw for bioconversion to ethanol: Focusing on pretreatment at high solids content. Bioresour. Technol. 100: 3048-3053.

11. Dunaway, K. W., R. K. Dasari, N. G. Bannett, and R. E. Berson (2010) Characterization of changes in viscosity and insoluble solids content during enzymatic saccharification of pretreated corn stover slurries. Bioresour. Technol. 101: 3575-3582.

12. Ahn, D. J., S. K. Kim, and H. S. Yun (2012) Optimization of pretreatment and saccharification for the production of bioethanol from water hyacinth by Saccharomyces cerevisiae. Bioprocess Biosyst. Eng. 35: 35-41.
13. Kuhad, R. C., R. Gupta, Y. P. Khasa, and A. Singh (2010) Bioethanol production from Lantana camara (red sage): Pretreatment, saccharification and fermentation. Bioresour. Technol. 101: 83488354.

14. Jang, J. S., Y. K. Cho, G. T. Jeong, and S. K. Kim (2012) Optimization of saccharification and ethanol production by simultaneous saccharification and fermentation (SSF) from seaweed, Saccharina japonica. Bioprocess Biosyst. Eng. 35: 11-18.

15. Nichols, N. N., L.N. Sharma, R. A. Mowery, C. K. Chambliss, G. P. V. Walsum, B. S. Dien, and L. B. Iten (2008) Fungal metabolism of fermentation inhibitors present in corn stover dilute acid hydrolysate. Enzyme Microb. Technol. 42: 624-630.

16. Kim, J. D., Y. H. Yoon, T. S. Shin, M. Y. Kim, H. S. Byun, S. J. Oh, and H. J. Seo (2011) Bioethanol production from seaweed Ulva pertusa for environmental application. Korean society for Biotechnol. Bioeng. Jour. 26: 317-322.

17. Karimi, K., G. Emtiazim, and M. J. Taherzadeh (2006) Ethanol production from dilute-acid pretreated rice straw by simultaneous saccharification and fermentation with Mucor indicys, Rhizopus oryzae, and Saccharomyces cerevisiae, Enzyme Microb. Technol. 40: 138-144. 